\title{
Metformin: Is it a Truly Magic Drug?
}

\section{Mervat M El-Eshmawy*}

Internal Medicine Department, Faculty of Medicine, Mansoura University, Egypt

*Corresponding author: Mervat M El-Eshmawy, Internal Medicine Department, Mansoura Specialized Medical Hospital, Faculty of Medicine, Mansoura University,

\section{Editorial}

Volume 3 Issue 2

Received Date: March 27, 2018

Published Date: April 02, 2018

Egypt, Email: mervat2040@yahoo.com

\section{Editorial}

Metformin has been the mainstay of therapy for type 2 diabetes (T2D) for many years; it has been used for its glucose-lowering effect since 1957 in Europe and 1995 in USA. Besides being highly effective in improving glycemic control, metformin has also a low risk of hypoglycemia. Metformin remains at the head of management algorithms for T2D, either as mono therapy or in combination with sulfonylureas, thiazolidinediones and insulin.

Recently, metformin has been investigated as an adjunctive therapy in poorly controlled type 1 diabetes [1]; the addition of metformin to insulin therapy leads to decreased average glucose concentrations and insulin dose requirement, as well as lowered metabolic syndrome prevalence after 1 year of treatment. However, the addition of metformin to insulin therapy is still under debate and not formally recommended in type 1 diabetes [2]. Larger placebo-controlled studies are needed to determine the long-term effects of metformin adjunctive therapy on poorly controlled type 1 diabetes.

The clinical indications of metformin therapy have expanded from T2D to gestational diabetes mellitus, polycystic ovary syndrome (PCOS), metabolic syndrome and diabetes prevention [3]. However, several studies have reported conflicting results regarding the role of metformin in PCOS and the accumulating evidence on the efficacy of metformin has been disappointing. The lack of an emphatic or overwhelming efficacy is largely due to the patients' variability in phenotypes and their metabolic parameters.

Moreover, this drug can positively influence multiple cardiovascular risk markers, including lipid profile
[4], fatty liver [5] and modulate inflammatory markers [6]. Metformin is the first anti-diabetic drug to display cardioprotective properties as shown in long-term randomized clinical trials [7]. However, many promising results are not without dispute. For example, whether metformin treatment can improve cardiovascular morbidity and mortality remains controversial.

Additionally, metformin has been considered to be one of the most promising drugs to target dementia and its related disorders; a growing body of evidence suggests that metformin is associated with a reduction in cognitive impairments in both T2D patients [8] and non-diabetic subjects [9]. However, the efficacy of metformin in improving cognitive function is still controversial; a study done by Moore et al. have shown that administration of metformin rather increased the risk of cognitive impairments [10], whereas Bang et al. have observed neither deleterious effects nor beneficial effects of metformin on cognitive function [11].

Epidemiological studies have also shown that metformin use is associated with a lower incidence and mortality of numerous cancers, particularly in patients with T2D [12,13] putting the drug into the cancer research spotlight. In addition, metformin sensitizes tumor cells to traditional chemo-drugs as well as irradiation therapy $[14,15]$. With regards to patients without diabetes, one study has demonstrated that metformin is associated with a lower risk of colorectal carcinogenesis [16]. However, metformin therapy did not reduce the risk of breast or prostate cancer [17].

Currently, the detailed mechanisms for the anti-tumor activity of metformin remain elusive. Further studies have 


\section{Diabetes and Obesity International Journal}

demonstrated that metformin has a direct antitumor effect in vivo and in vitro, which may repress the proliferation of tumor cells, and induce apoptosis, autophagy and cell cycle arrest [18-20]. An in vitro study has demonstrated that metformin may activate AMPinducible protein kinase (AMPK) and down regulate p70S6K/pS6 protein to inhibit the growth of tumor cells [21]. Metformin also suppresses the secretion of IGF-1, IGF-2, leptin, and the tissue metallopeptidase inhibitor 1 and decreases the lipid accumulation during adipocyte differentiation [22].

The question arises is whether metformin may become an alternative cancer adjuvant therapy, providing a novel approach for cancer prevention and treatment? The potential anti-tumor activity of metformin in numerous cancers remains controversial and needs long-term randomized controlled trials.

Metformin; the most frequently prescribed antidiabetic treatment worldwide; has gained attention for its pleiotropic effects; however the apparently promising effects in many diseases are challenged by conflicting observations. So, more work is needed to establish its right place with this regards.

\section{References}

1. Beysel S, Unsal IO, Kizilgul M, Caliskan M, Ucan B, et al. (2018) The effects of metformin in type 1 diabetes mellitus. BMC Endocr Disord 18(1): 1.

2. DeGeeter M, Williamson B (2016) Alternative agents in type 1 diabetes in addition to insulin therapy: Metformin, alpha-Glucosidase inhibitors, Pioglitazone, GLP-1 agonists, DPP-IV inhibitors, and SGLT-2 inhibitors. J Pharm Pract 29: 144-159.

3. Cicero AF, Tartagni E, Ertek S (2012) Metformin and its clinical use: new insights for an old drug in clinical practice. Arch Med Sci 8: 907-917.

4. Salpeter SR, Buckley NS, Kahn JA, Salpeter EE (2008) Meta-analysis: metformin treatment in persons at risk for diabetes mellitus. Am J Med 121(2): 149-157.

5. Kita Y, Takamura T, Misu H, Ota T, Kurita S, Takeshita Y, et al. (2012) Metformin prevents and reverses inflammation in a non-diabetic mouse model of nonalcoholic steatohepatitis. PLoS One 7(9): e43056.

6. Andrews M, Soto N, Arredondo M (2012) Effect of metformin on the expression of tumor necrosis factor- $\alpha$, Toll like receptors $2 / 4$ and $C$ reactive protein in obese type-2 diabetic patients [Spanish]. Rev Med Chil 140: 1377-1382.

7. Roussel R, Travert F, Pasquet B, Wilson PW, Smith SC, et al. (2010) Metformin use and mortality among patients with diabetes and atherothrombosis. Arch Intern Med 170(20): 1892-1899.

8. Cheng YY, Leu HB, Chen TJ, Chen CL, Kuo CH, et al. (2014) Metformin-inclusive therapy reduces the risk of stroke in patients with diabetes: a 4-year follow-up study. J Stroke Cerebrovasc Dis 23: e99-e105.

9. Luchsinger JA, Perez T, Chang H, Mehta P, Steffener J, et al. (2016) Metformin in amnestic mild cognitive impairment: results of a pilot randomized placebo controlled clinical trial. J Alzheimers Dis 51(2): 501514.

10. Moore EM, Mander AG, Ames D, Kotowicz MA, Carne RP, et al. (2013) Increased risk of cognitive impairment in patients with diabetes is associated with metformin. Diabetes Care 36(10): 2981-2987.

11. Bang E, Lee B, Park JO, Jang Y, Kim A, et al. (2018) The Improving Effect of HL271, a Chemical Derivative of Metformin, a Popular Drug for Type II Diabetes Mellitus, on Aging-induced Cognitive Decline. Exp Neurobiol 27(1): 45-56.

12. Jalving M, Gietema JA, Lefrandt JD, de Jong S, Reyners AKL, et al. (2010) Metformin: Taking away the candy for cancer?. Eur J Cancer 46: 2369-2380.

13. DeCensi A, Puntoni M, Goodwin P, Cazzaniga M, Gennari A, et al. (2010) Metformin and Cancer Risk in Diabetic Patients: A Systematic Review and Metaanalysis. Cancer Prev Res 3: 1451-1461.

14. Wang Z, Lai ST, Ma NY, Deng Y, Liu Y, et al. (2015) Radiosensitization of metformin in pancreatic cancer cells via abrogating the G2 checkpoint and inhibiting DNA damage repair. Cancer Lett 369: 192-201.

15. Zhang HH, Guo XL (2016) Combinational strategies of metformin and chemotherapy in cancers. Cancer Chemother Pharmacol 78(1): 13-26.

16. Hosono K, Endo H, Takahashi H, Sugiyama M, Sakai E, et al. (2010) Metformin suppresses colorectal aberrant crypt foci in a short-term clinical trial. Cancer Prev Res (Phila) 3(9): 1077-1083.

17. Currie CJ, Poole CD, Gale EA (2009) The influence of glucose-lowering therapies on cancer risk in type 2 diabetes. Diabetologia 52: 1766-1777. 


\section{Diabetes and Obesity International Journal}

18. Emami Riedmaier A, Fisel P, Nies AT, Schaeffeler E, Schwab M (2013) Metformin and cancer: From the old medicine cabinet to pharmacological pitfalls and prospects. Trends Pharmacol Sci 34(2): 126-135.

19. Rizos CV, Elisaf MS (2013) Metformin and cancer. Eur J Pharmacol 705(1-3): 96-108.

20. Bost F, Sahra IB, Le Marchand-Brustel Y, Tanti JF (2012) Metformin and cancer therapy. Curr Opin Oncol 24: 103-108.
21. Klubo-Gwiezdzinska J, Costello J, Jr Patel A, Bauer A, Jensen $\mathrm{K}$, et al. (2013) Treatment with metformin is associated with higher remission rate in diabetic patients with thyroid cancer.J Clin Endocrinol Metab 98: 3269-3279.

22. Fuentes-Mattei E, Velazquez-Torres G, Phan L, Zhang F, Chou PC, et al. (2014) Effects of obesity on transcriptomic changes and cancer hallmarks in estrogen receptor-positive breast cancer. J Natl Cancer Inst 106 (7). 